\title{
Extending the Role of Technology Continuance Theory and Task Technology Fit with Pre-Technology Adoption and Post-Technology Adoption Behaviors
}

\author{
Shumaila Naz ${ }^{1}$, Ahsan Akbar ${ }^{2 *}$, Petra Poulova ${ }^{2}$, José Moleiro Martins ${ }^{3,4}$, Syed Arslan Haider ${ }^{5}$, Mário Nuno \\ Mata $^{4}$, Shabnam Khan ${ }^{6}$, Kalpina Kumari ${ }^{1}$ \\ 1 Faculty of Business Administration, Iqra University, Karachi 75500, Pakistan, shumaila.superior@gmail.com; \\ kalpina@iqra.edu.pk \\ 2 Department of Informatics and Quantitative Methods, Faculty of Informatics and Management, University of Hradec \\ Kralove, 500 03, Hradec Králové, Czech Republic;ahsan.akbar@uhk.cz; petra.poulova@uhk.cz \\ 3 Instituto Universitário de Lisboa (ISCTE-IUL), Business Research Unit (BRU-IUL), 1649-026 Lisboa, Portugal, e-mail: \\ zdmmartins@gmail.com \\ 4 ISCAL (Instituto Superior de Contabilidade e Administração de Lisboa), Instituto Politécnico de Lisboa, Avenida \\ Miguel Bombarda, 20, 1069-035 Lisboa; e-mail: mnmata@iscal.ipl.pt \\ 5 Department of Management, Sunway University Business School (SUBS), Sunway University, No 5, Jalan Universiti, \\ Bandar Sunway,47500 Selangor Darul Ehsan, Malaysia; 3 Email: haidershah24@gmail.com \\ 6 Department of Management Sciences, Women University Swabi; e-mail: shabnam.khan@wus.edu.pk \\ *Correspondence: $\underline{\text { ahsan.akbar@uhk.cz }}$
}

\begin{abstract}
The development in information technology has played an influential role in transforming the restaurant industry services. Therefore, this research's main agenda is to investigate factors that motivate employees to adopt and continue using information technology services by integrating two famous information system (IS) theories, namely, task technology fit (TTF) and technology continuance theory (TCT). The extant integrative perspective model details the cause-effect relationship between technology adoption and continuance intention. The positivist paradigm forms the basis of this research design, and the approach followed is quantitative research. Using the stratified random sampling technique, the empirical data was collected from 417 restaurant industry employees in the US (United States) on a five-point Likert scale. The PLS-SEM technique was utilized to analyze data while using Smart PLS 3 because of its suitability and wider application currently in the hospitality sector. Results suggest that the recently developed integrated technology continuance research model has considerable influence on predicting pre- and post-adoption behavior with continuance intention for technology usage within the restaurant industry. All hypotheses were found significant except one for the direct association of hedonic motivation and continuance intention of technology adoption. Moreover, the results revealed that factors like perceived security \& information privacy and assisting conditions were the most important factors in determining the usage of information technology with continuance intention. Unlike previous research studies that focus majorly only on issues before adoption of informational technology usage, the current focus on investigating continuance intention toward information technology usage by focusing on factors that can also boost post-adoption behavior and pre-adoption usage information technology.
\end{abstract}

Keywords: Continuance intention, Technology continuance theory, Task technology fit, Restaurant Industry

\section{Introduction}

One of the primary industries in the USA comprises the service industry [1]. The restaurant industry is one of the leading players in the service industries. At the end of 2017, the projected sales for the restaurant industry were over $\$ 798 \mathrm{bn}$ [2] and presented bright prospects for growth in 2019 [3]. In addition, the food services observed a steady increase 
from $\$ 532.2$ bn to $\$ 727.0$ bn from 2010 to 2020, respectively [4]. As part of the total personal consumption expenditures, food services accounted for 5.67 percent [5], whereas it made up $4 \%$ of the US GDP in 2016 [4]. Hence, the restaurant industry can justifiably be called one of the most rapidly expanding industries in the US.

Recent decades have led to the development of an entire class of scientific knowledge that concerns the development and acceptance of information and communication technologies (ICT), which has been consolidated in the service industry [6]. At the same time, the restaurant industry has been impacted with ICT services equally [7], where technological developments have affected the restaurant businesses to a greater extent. This is primarily due to the thriving telecommunications industry, improvements in computer capabilities and the growth and expansion of software to support the delivery of services [3]. Moreover, many financial investments have been made in the IT sector to uplift the service industry. This is to decrease costs, increase revenue and better the quality of customer service imparted [8]. Both academic experts and industry leaders have acknowledged the undeniable contribution of information communication technology (ICT). They have been mindful of its contributions to the service industry [9]. Prior studies have proven that investment in information technology (IT) boosts revenue growth and saves costs [10]. Furthermore, by implementing ICT systems, restaurants have seen a positive correlation between ICT usage and competitive advantage [11].

Despite the attractive outcomes and benefits that ICT has offered its users, the acceptance rate of these specialized softwares and tools is not as widespread in restaurants as expected. Tuomi et al. [12] note that many restaurants' businesses still fail to make the most of available technology due to security and privacy concerns. Moreover, according to Ashcroft et al. [13], where restaurant managers in the US seem to be generally open-minded concerning technology, they are at the same time slightly skeptical about adopting new IT systems due to the absence of their supportive task characteristics and facilitating conditions. At the same time, some managers more open to ICT innovation feared that their businesses could not bear the increased costs and complexity resulting from greater customer demand. Further, a few bad experiences (e.g., glitches, issues with connectivity) with one system were often enough to cause apprehension towards adopting new technology. Thus, most common ICTs used in the studied restaurants were only smart order taking, smart reservation systems and smart advertising and customer relations management. The majority of HR and other administrative tasks were still typically done manually and when this combined with high turnover, has acted to constrain their productivity growth [14]. Overall, however, the need to keep up with the times is recognized, with one General Manager explaining that "if you're not part of the technology change, you're going to be out - you're going to be left behind". Therefore, Lambert [15] argued that to sustain economic growth and increase competitiveness, restaurant businesses must continually innovate and support their functions with new developing high-teach systems.

Furthermore, in recent times, a lot of researchers have taken up the topic of investigating IT usage patterns, particularly in the pre-adoption phase [16], although very little has been elaborated upon the usage of information technology on continuance intention [17]. Previous studies suggest that continual use of IT is essential to ensure organizational success and guarantee sustainability rather than just initial adoption [18]. Thus, investigating a combined model of what factors boost users' (employees') confidence to adopt and to continue with the usage of information technology in different types of US restaurants is much needed.

Additionally, in the last decade, the concept of user's behavior towards adoption and using information technology has been largely argued and investigated within the con- 
text of many other industries such as banking, education, tourism etc.[19,20]. However, very little research in the past has been found to focus on how this underlying mechanism of pre and post-technology adoption could be applied within the restaurant industry of Pakistan [21]. Hence, to cover up the breaks in the existing literature, this study takes up the restaurant industry of Pakistan as the focus of the current research. Thus, the findings and conclusion of this research will be a significant value addition in the present literature of adoption of technology within the restaurant industry.

Therefore, considering the above argument, the current study is focused on filling the research gap on examining the factors that can encourage pre and post-adoption behaviors of information technology among its users within the context of restaurant businesses. In the context of pre-adoption behaviors, the impact of three different factors, i.e., task characteristics, task technology fit, and technical characteristics, has been investigated on employees' hedonic motivation. Afterwards, focused on how this hedonic motivation can lead towards their continuance intention and make them actual users of high-tech systems within the restaurant industry. In the context of post-adoption behaviors, how perceived security and privacy factors and facilitating condition of technology make their users more inclined to continue with the usage of information technology have also been taken into consideration. This study is hence centered on investigating this phenomenon in a multifaceted way.

\section{Theoretical Context and Hypotheses Development}

The study at hand considers two overarching theories i.e., task technology fit (TTF) and technology continuance theory (TCT), to investigate the usage of information technology at the initial adoption and to lead towards its continuance intention. Goodhue and Thompson [22] introduced the TTF model, highlighting features related to technology and operational tasks. As per the TTF model, the acceptance rate of technology is likely to be higher when it facilitates user and help them to boost their task performance. Subsequently, Liao established TCT [23] and was found to have studied the effect of information system (IS) dimensions on the continuance intention of the user. Hence, the TCT implies that for services to be implemented successfully, they must be used in the long-term rather than just being adopted in the initial phase [24]. Both the TTF and the TCT models have their pros and cons. For example, the TCT model overlooks task characteristics and technology characteristics that directly impact user behavior toward the adoption of technology.

At the same time, the TTF model eliminated the IS continuance factors such as satisfaction, perceived usefulness, and confirmation. Lin [25] established that to gain a holistic perspective of task and technology characteristics in forecasting and application of technology, the TTF model must include other IS continuance factors. To reiterate this, Rahi [26] argued that "an integrative perspective model provides a complete account of the causal mechanism underlying the relationships and unique insight that cannot be obtained from single theory-driven model". Thus, an amalgamation of the TTF model and TCT for predicting the usage of information technology in pre-adoption and its continuance usage is an addition in theory and practice alike. Fig 1 shows the extended technology continuance model (TCM) with a causal relationship.

\section{Literature Review}

\subsection{Task Characteristics and Hedonic Motivation (HM)}

In the task-technology fit theory (TTF), tasks are a set of activities that individuals undertake in converting inputs to outputs in a way that satisfies their information needs 
$[22,27]$. Moreover, task characteristics can be defined as characteristics of a task that can be completed by using information communication technologies. Additionally, the first new construct that the Unified Theory of Acceptance and Use of Technology 2 (UTAUT2) introduces is hedonic motivation (HM), which is defined as the element of fun that consumers derive during the usage of technology [28,29].

According to the job characteristics model, designed by Hackman [30], the task assumes a major role in employee motivation which inevitably is responsible for workplace satisfaction [31]. When employees feel stuck in a repetitive and mundane job, their motivation to outperform subsides. In contrast, an eventful or demanding job stimulates performance due to increased motivation. Oerlemans and Bakker [32] also proved by their study that when a job's characteristics motivate the employee, his happiness levels while doing the given task/activity at work are higher. Moreover, Sarti \& Torre [33] also said that work happiness is an amalgamation of four main job characteristics i.e., task variety, task significance, task identity, and feedback. Therefore, built on various existing literature on this topic and supporting opinions, the following hypothesis has been developed concerning task characteristics and hedonic motivation:

H1. Task characteristics have a significant impact on hedonic motivation.

\subsection{Task and Technology Fit and Hedonic Motivation (HM)}

The task technology-fit (TTF) is a term known to describe technology that facilitates an individual in completing their tasks proficiently. This is subsequently influenced by the interaction between the functionalities of the technology and the characteristics of the task [34]. The role of TTF has become quite monumental when it comes to analyzing the usage of technology in organizations [35]. Numerous studies have been carried out to study the positive influence of the TTF construct on the success factors of information systems (IS), namely motivational impact and user satisfaction [36,37]. As per Martins et al. [38], it is highly likely that a greater level of technology fitness will encourage users to keep using IT services with consistency. In the field of ICT, the significance of the role of TTF in encouraging users to adopt information systems has been confirmed by many studies [39]. These studies propose that IS directly affects motivation when there is a strong and positive correlation between the user's task requirements and the system's functionality. In addition, Sharif et al.[40], studied in-depth the effect of technology fit between technology and the user's task and how it influences the pleasure derived by individuals. They reiterated that the technology leveraged should be a good match with the task (or correspondence between its functionality and the task requirements) for it to positively influence individual pleasure, which in turn will ensure the continuance intention of technology usage.

Consistent with prior research, it can be justifiably said that the more appropriate the match is between technology and the work task, the higher is the user satisfaction and ultimately the motivation to use the technology. Consequently, the following hypothesis has been developed concerning task-technology fit and hedonic motivation:

H2. Task and technology fit has a significant impact on hedonic motivation.

\subsection{Technology Characteristics and Hedonic Motivation (HM)}

According to Goodhue [22], technology characteristics refer to "the different features of computer systems (hardware, software, and data) and user support services (training, helplines, etc.) provided to assist users in performing their tasks" [22]. Moreover, according to Alazab et al.[41], technology characteristics can be aptly called interface plat- 
forms (e.g. Transactional data analytics tools, apps and mobile devices) are used to perform particular tasks.

Martins et al. [38] found out that IS becomes more appealing when the adopted technology is useful and effective. In contrast, poor technology characteristics subside user's intention of continuing the usage of information technology. According to Goodhue [42], technology utilization and users' motivation are directly influenced by technology tools. Authors like Yen [43] have established that technology characteristics inadvertently influence the apparent ease of use, leading to users' continuance behavioral intentions. The same results are also confirmed by Ramayah [44], who stated a major impact of technology characteristics on the perceived ease of use and usefulness, which ultimately influence employee's pleasure for using information technology. Tam \& Oliveira [45] highlighted that users' motivation to adopt IT would decrease if information technology were less functional. Similarly, effective technology characteristics have a favorable impact on an individual's pleasure to use technology. Conversely, a poor technology function reduces the readiness to make efficient use of technology. Similarly, Lin et al.[46] stressed new technologies may be overlooked or concealed due to unintentional technological characteristics. Wixom \& Todd [47] also studied the effect of technology characteristics on users' satisfaction and found a significant relationship between the given variables. Therefore, based on the above arguments and discussion, the following hypothesis has been developed concerning technology characteristics and hedonic motivation.

H3. Technology characteristics have significant impact on hedonic motivation.

\subsection{Hedonic Motivation (HM) and Continuance Intention (CI)}

Continuance intention (CI) has been widely studied in regard with information systems and the acceptance of technology. Hence, it has been as an individual's preference or mental acceptability to implement a specific kind of behavior and use a technology by extension [48]. Hedonic motivation, alternatively known as perceived enjoyment, has a considerable impact on users' behavioral continuance intention towards technology usage [49]. In other words, the level of enjoyment derived by users ultimately determines the adoption and continued utilization of technology. As per Wang and Khan [50], a strong positive correlation exists between HM and CI. The same results are also confirmed by Al-Nuaimi \& Al-Emran [51], who reported that a major factor in ensuring technology acceptance and continuance intention for its usage is hedonic motivation.

According to Sharif \& Raza [52], the enjoyment of using technology is crucial to create the continuance intention of usage, especially in the context of the consumer as he performs the technology adoption on self-will [53]. Therefore, past researchers majorly cite hedonic motivation as a predictor variable of consumers' continuance intention in the household items [28,54] whereas, far less consideration has been paid to inspect the role of hedonic motivation as a predictor of employees' continuance intention in technology adoption at the workplace to perform their required task [55]. Therefore, this research has reversed the lens from customers to employees' perspective and has proposed the following hypothesis:

H4. Hedonic motivation has a significant impact on continuance intention.

\subsection{Continuance Intention (CI) and Actual Usage (AU)}

According to Aldholay et al.[56], actual usage (AU) is the real condition of the use of the system, which is measured as the amount of time used to interact with technology and 
the frequency of its usage. According to Irani et al.[57], the continuance intention (CI) is a factor that is considered important when adopting the technological stream. One of the most noticeable differences between earlier theories of acceptance and TAM (Technology Acceptance Model) is the presence of CI [58]. CI is a major precursor of usage behavior and is a prime indicator of how ready an individual is to act in a certain manner [59]. In TAM, both perceived usefulness (PU) and perceived ease of use (PEOU) have a direct influence on the continuance intention of an individual to deploy technology, which in turn stimulates its actual usage behavior [60]. In addition, the relationship between CI and $\mathrm{AU}$ has also been revealed as significant in the Decomposed Theory of Planned Behavior (DTPB) and the theory of planned behavior (TPB) models.

Consequently, there is much support in the form of existing literature that continuance intention is a critical precursor of technology adoption. More prominently, this correlation was reiterated and backed by numerous studies examining ICT adoption [61]. Therefore, past research has proved with strong evidence that CI has a drastic influence on AU [62]. It is imperative to mention that the effect of $\mathrm{CI}$ is more predictable on AU when the individuals have previous experience with that technology [63]. As established by prior researches, this study has also considered both CI and AU as dependent variables in the theoretical framework. This leads us to expect that CI will directly impact forecasting the actual usage behavior of employees conform to adopt the new information technology system within their organizational setting. Therefore, the following hypothesis has been proposed:

H5. Continuance intention has a significant impact on actual usage.

\subsection{Perceived Security E Information Privacy, Continuance Intention and Actual Usage}

In this study, perceived security is defined as the perception that the employee will take suitable actions to make sure that technology usage is secure and risk-free [64]. On the other hand, according to Degirmenci [65], information privacy is the capacity of each person to have control over their private information. They have the right to hold or release as much information as is necessary, whether it is on digital or non-digital platforms. As information technologies have grown more ubiquitous, so have the threats to the enterprise, the device, and the individual using those devices [66].

As security and privacy issues appear to be of utmost importance in the usage of information technology, the impact of perceived security and information privacy has been studied in a wide range of areas related to technology implementation and adoption. Arpaci et al. (2015), in their study, established that information privacy and security concerns had a direct impact on attitude, which in turn affected continuance intention. Alexandrou and Chen [65] explored the impact of perceived security risk on intention. They found that the perceived security risks harmed the intention associated with the technology usage. Almadhoun et al.[68] explored the impact of information privacy, perceived security, and trust on the readiness for information sharing and developing relationships on social networking sites (SNS). Their findings suggested that perceived security, information privacy, and trust had a significant impact on willingness to share information and their behavioral intention to adopt the technology, which ultimately impacts its actual usage. Studies by Dhillon et al. [69] also found strong evidence to support perceived security and information privacy impacted the purpose of adopting information technology. When investigating ICT system adoption, Princi and Krämer [70] found that perceived privacy risk negatively impacted perceived security, which in turn impacted its continuance intention to adopt. Consistent with prior research, in the domain of the restaurant industry, it is argued that if the employees feel that their security and information privacy concerns are being well protected, then their behavioral 
continuance intention and actual usage of ICT will be unsurprisingly enhanced. Therefore, the following hypotheses have been proposed:

H6. Perceived security \& privacy has a significant impact on continuance intention.

H7. Perceived security \& privacy has a significant impact on actual usage.

\subsection{Facilitating Condition, Continuance Intention and Actual Usage}

When we talk about facilitating conditions, we mean the extent to which a person can rely on the organizational and technical infrastructure to assist them in making use of the system [71] and supporting factors in using a system. These include an external help desk, assisting supervisor, etc. Therefore, facilitating conditions are primarily known to refer to the accessibility of adequate assets and assistance for people to use and fully exploit the new implemented technology within their organizational structure [72]. Several scholars found that facilitating conditions have an invariable positive influence on how innovation is incorporated [73]. Subsequently, insufficient information, scarce resources, lack of timely support and assistance can serve as a roadblock in the acceptance level of web-based technology [74]. It means that employees are required to possess the essential resources and information to use newly implemented IT systems within their structure to perform their required tasks with more efficiency. If users do not own these resources and knowledge, they may not show their intentions to continue its usage [75]. Therefore, in the IS domain, facilitating such conditions are key to impacting an individual's intentions regarding system usage. Suitable introduction, training, and back-up are needed prior to a company expecting its employees to implement any such innovations to make sure that the technology has been fully exploited [76].

Furthermore, facilitating conditions can serve as a great adoption enabler if the necessary resources and facilities are sufficient. Hence, many people can display positive attitudes towards the implementation of information and communication technology (ICT). On the other hand, facilitating conditions can lead to the buildup of negative sentiments and behavior towards ICT if those conditions are not found satisfying to the users. As per Merhi et al. [77], perceived facilitating conditions significantly affect the behavioral intention for technology adoption, which translates to actual technology usage. It is believed that if an offers more facilitating conditions, it subsequently enhances definite usage. Therefore, usage of information technology continues to be largely dependent on the presence of multiple required resources and sound infrastructure, such as technical support availability, system compatibility, availability of internet connection etc. Therefore, based on the given discussion, it is believed that if employees can access required resources and gain needed knowledge and have the necessary support to use information technology infrastructure, they will be more likely to adopt ICT system easily and will be the actual users. Consequently, the following hypotheses are being proposed:

H8. Facilitating conditions have a positive effect on continuance intention.

H9. Facilitating conditions have a positive effect on actual usage.

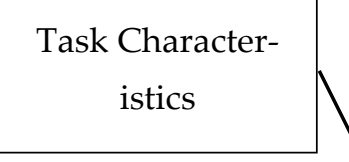

H1
Perceived Security \& Information Privacy 


\section{Fig. 1 Proposed Research Model}

\section{Research Methodology}

\subsection{Questionnaire and pilot testing}

To measure the underlying constructs, the items (mentioned in table 1) were adapted from precursory scales used and tested by previous researchers. Moreover, few minor modifications were made to make it adjustable with the objectives of the current study, specifically in the context of the restaurant industry located within the US (United States). The comprehensive model presented the causal mechanism of factors that motivated the continuous adoption/usage of technology. To explain the proposed causal association of variables, the adapted scales were measured on a five-point Likert scale; strongly disagree (1) to strongly agree (5). For all selected variables, the detail of scale adaption is given as below;

8 -items scale of task characteristics was adapted from previous studies $[22,48,78]$.

5 -items scale of task-technology fit was adapted from previous studies [78,79].

8 -items scale of technology characteristics was adapted from previous studies [22,48,78].

3 -items scale of hedonic motivation was adapted from previous studies [80,81].

The 10 -items scale of perceived security and information privacy was adapted from previous studies [82-84].

6 -items scale of facilitating condition was adapted from previous studies $[80,85,86]$.

3 -items scale of continuance intention was adapted from a previous study [53].

4 -items scale of actual usage was adapted from previous studies $[87,88]$.

In total, 47 questions were asked to get the response against our research model (fig. 1) in the context of the restaurant industry of the USA. The content validity of the instrument was ensured by panel of academicians and field experts as well. The panel comprises of two academicians (specialized in hotel management) and two hotel managers. To ensure the in-depth accuracy of the instrument, questionnaires were sent to the 50 respondents to IT staff in the restaurant for conducting a pilot study. Moreover, it was specified that respondents for the pilot study must have more than 2-years' experience in the relevant 
industry to ensure accuracy of knowledge being queried. As per the feedback of respondents, minor alterations were made in the given instrument. Furthermore, a reliability analysis was conducted to ensure the internal consistency of the scale used in the study, reflecting the required Cronbach alpha value for reliable data set for further use (refer to table 1).

\subsection{Sample design, Participants, and data collection}

Following the positivism paradigm, this study used a quantitative approach to examine the integrated technology continuance research model's proposed direct and indirect association. For data collection, the services of professional agency Amazon Mechanical Turk (MTurk) were hired to collect data from the respondents in the restaurants' industry of the USA. The criteria for the required sample of the study was made clear in prior. Using stratified random sampling, strata (group of respondents) were defined from the most fascinating and most visited cities of the USA; New York, Los Vegas, Washington DC, Los Angeles, Orlando and San Diego. The restaurants operated in the above-mentioned cities are among the most technological -advanced cities to get better insights about the technological adoption, actual usage and continuance intention. The sample selected for the study includes senior technology staff (involved in the adoption and usage of emerging job-related technologies), hotel managers, and owners to get better acumen about the objectives of the study. It is further specified that respondents must have more than two years of experience in the relevant industry and fall in the age group of above 25 years. Total 550 questionnaires were circulated, and 417 duly filled questionnaires were returned, reflecting 75.81\% response. Moreover, 12 questionnaires were also not usable due to missing values, and the remaining 402 valid responses were finally used for the analysis purpose.

\section{Analysis and Findings}

The PLS-SEM technique was utilized for analyzing data while using Smart PLS 3 because of its suitability and wider application currently in the hospitality sector [89]. This study was underpinned with the theories of task technology fit (TTF) and technology continuance theory (TCT) to explore the adoption of information technology and continuance intention of its usage in US restaurants. PLS-SEM is considered a powerful instrument when the foremost objective of using structural modelling is to elucidate and estimate latent studied constructs $[90,91]$. Additionally, PLS-SEM is assumed to be a flexible technique for model assessment. Further, it does not confine for sample size and data normality requirements, making it convenient to continue analysis [92]. Therefore, the extant research adopted this procedure to circumvent sample size and data normality concerns. Moreover, the research model of the paper was multifaceted using two underpinned theories, and PLS can be applied wherein complex structural models accompanied multiple constructs. Subsequently we applied PLS algorithm followed by bootstrapping technique for examining measurement modelling and structural modelling, respectively.

\subsection{Measurement model assessment}

The measurement model was assessed through convergent validity by analyzing factor loadings, average variance extract (AVE), and competitive reliability (CR). Referring to 
Table 1, factor loadings for all studied constructs surpassed the suggested value of 0.60 . Likewise, all values of CR surpassed the suggested value of 0.70. All AVE values for all studied constructs in the study surpassed the suggested value of 0.50 [92]. It is important to mention that all the items with the lowest factor loadings of less than a threshold value of 0.50 were obliterated to ensure data adequacy and use for further analysis.

Table 1: Convergent Validity

\begin{tabular}{|c|c|c|c|c|c|}
\hline Construct & $\begin{array}{l}\text { Factor } \\
\text { (Cronbach's } \\
\text { a) }\end{array}$ & Items & $\begin{array}{l}\text { Load- } \\
\text { ings }\end{array}$ & CR & AVE \\
\hline \multirow[t]{4}{*}{ Actual usage } & 0.88 & AU1 & 0.858 & 0.917 & 0.734 \\
\hline & & AU2 & 0.866 & & \\
\hline & & AU3 & 0.869 & & \\
\hline & & AU4 & 0.834 & & \\
\hline \multirow[t]{3}{*}{ Continues Intention } & 0.878 & CI1 & 0.922 & 0.924 & 0.803 \\
\hline & & $\mathrm{CI} 2$ & 0.881 & & \\
\hline & & $\mathrm{CI} 3$ & 0.885 & & \\
\hline \multirow[t]{5}{*}{ Facilitating conditions } & 0.841 & FC1 & 0.721 & 0.889 & 0.619 \\
\hline & & FC2 & 0.625 & & \\
\hline & & FC4 & 0.864 & & \\
\hline & & FC5 & 0.848 & & \\
\hline & & FC6 & 0.847 & & \\
\hline \multirow[t]{3}{*}{ Hedonic motivation } & 0.895 & HM1 & 0.948 & 0.935 & 0.828 \\
\hline & & HM2 & 0.848 & & \\
\hline & & HM3 & 0.931 & & \\
\hline \multirow[t]{7}{*}{ Perceived security \& privacy } & 0.878 & PS1 & 0.797 & 0.906 & 0.552 \\
\hline & & PS2 & 0.838 & & \\
\hline & & PS3 & 0.803 & & \\
\hline & & PS4 & 0.78 & & \\
\hline & & PS5 & 0.767 & & \\
\hline & & PS9 & 0.725 & & \\
\hline & & PS10 & 0.739 & & \\
\hline \multirow[t]{4}{*}{ Task Characteristics } & 0.737 & TC1 & 0.586 & 0.848 & 0.6 \\
\hline & & TC2 & 0.84 & & \\
\hline & & TC5 & 0.894 & & \\
\hline & & TC8 & 0.865 & & \\
\hline \multirow[t]{6}{*}{ Technology Characteristics } & 0.85 & TEC1 & 0.789 & 0.889 & 0.573 \\
\hline & & TEC3 & 0.776 & & \\
\hline & & TEC4 & 0.764 & & \\
\hline & & TEC6 & 0.751 & & \\
\hline & & TEC7 & 0.636 & & \\
\hline & & TEC8 & 0.813 & & \\
\hline
\end{tabular}




\begin{tabular}{|c|c|c|c|c|c|}
\hline \multirow[t]{4}{*}{ Task Technology Fit } & \multirow[t]{4}{*}{0.788} & TTF1 & 0.775 & \multirow[t]{4}{*}{0.853} & 0.562 \\
\hline & & TTF2 & 0.81 & & \\
\hline & & TTF3 & 0.869 & & \\
\hline & & TTF4 & 0.858 & & \\
\hline
\end{tabular}

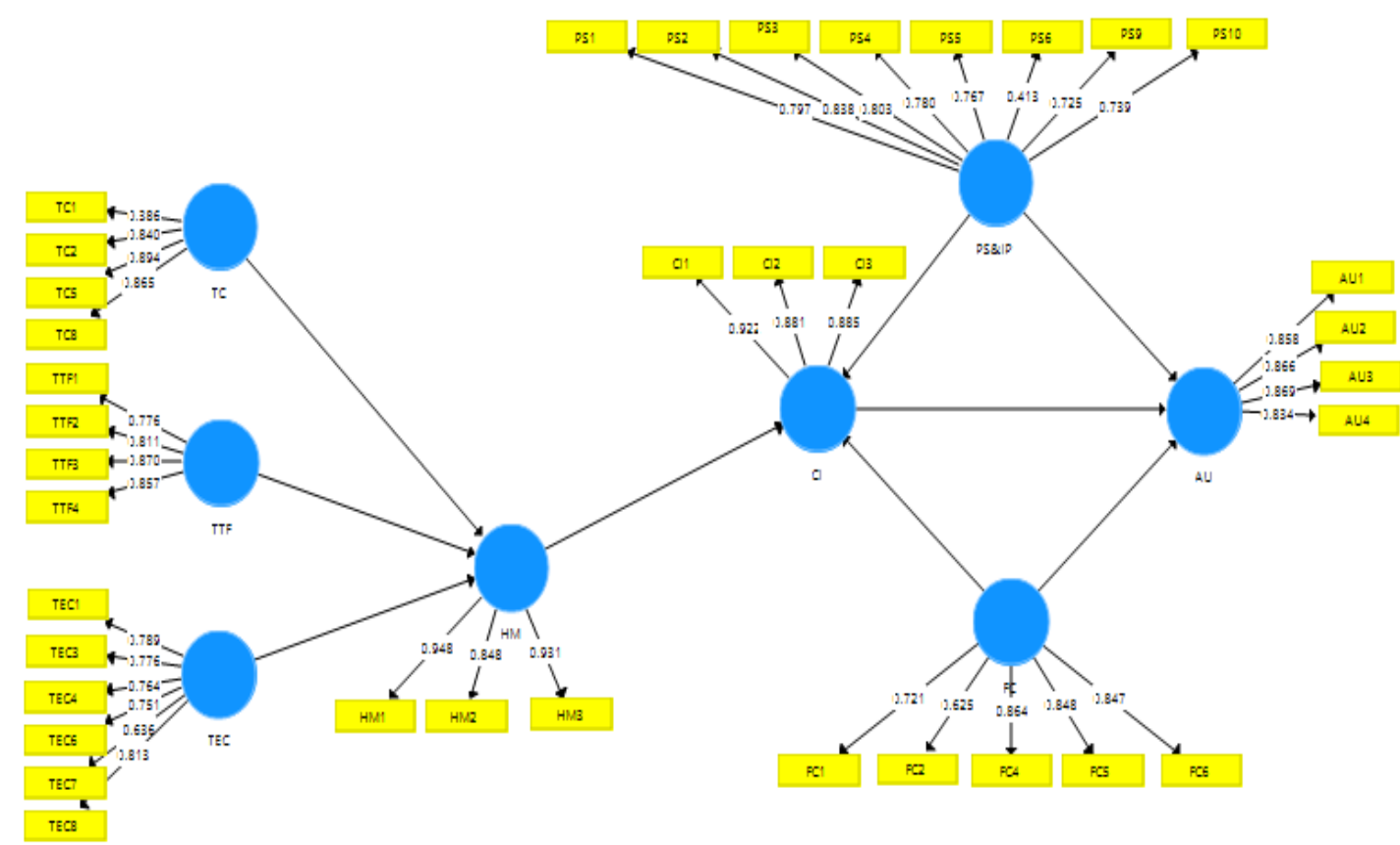

Fig. 2 Measurement Model Assessment

\subsection{Discriminant validity}

There is an ongoing debate that the Heterotrait-Monotrait Ratio (HTMT) should be preferred over the Fornell-Larcker criterion (FLC) because of its inability to measure discriminant validity in several research situations [93]. Consequently, both the FLC and HTMT ratios were used to evaluate the discriminant validity of all studied constructs. Table 2 demonstrated that discriminant validity was ensured for all constructs using both approaches set values.

Table 2: Discriminant Validity

\begin{tabular}{lllllllll}
\hline \multicolumn{2}{l}{ HTMT Criteria } & & & & & & \\
\hline & AU & CI & FC & HM & PS\&IP & TC & TEC & TTF \\
\hline AU & & & & & & & & \\
CI & 0.342 & & & & & & & \\
\end{tabular}




\begin{tabular}{llllllll} 
FC & 0.618 & 0.418 & & & & & \\
HM & 0.179 & 0.146 & 0.448 & & & & \\
PS\&IP & 0.647 & 0.375 & 0.757 & 0.487 & & & \\
TC & 0.352 & 0.361 & 0.656 & 0.472 & 0.535 & & \\
TEC & 0.5 & 0.367 & 0.726 & 0.496 & 0.767 & 0.73 & \\
TTF & 0.499 & 0.401 & 0.773 & 0.461 & 0.755 & 0.66 & 0.708 \\
\hline Fornell and Larcker Criteria & & & & & \\
\hline AU & 0.857 & & & & & & \\
CI & -0.303 & 0.896 & & & & & \\
FC & -0.54 & 0.363 & 0.787 & & & & \\
HM & -0.163 & 0.13 & 0.391 & 0.91 & & & \\
PS\&IP & -0.585 & 0.327 & 0.664 & 0.429 & 0.743 & & \\
TC & -0.283 & 0.295 & 0.528 & 0.381 & 0.434 & 0.775 & \\
TEC & -0.43 & 0.318 & 0.624 & 0.441 & 0.666 & 0.582 & 0.757 \\
TTF & -0.424 & 0.287 & 0.649 & 0.427 & 0.64 & 0.532 & 0.614 \\
\hline
\end{tabular}

\subsection{Structural model assessment}

After the assessment of the measurement model, the structural model was measured. For structural model assessment, the significance of the model was assessed based on beta values, t-values, and lower and upper limit values. The hypotheses were evaluated for direct effects while performing the bootstrapping technique in Smart PLS 3 [94,95]. Results of path coefficients were used to measure the direct hypotheses (refer to Table 3). Relationships were estimated by using prescribed threshold values $(t>1.645 ; \mathrm{P}<0.05)$. According to set standard values, all hypotheses were supported except one.

Table 3: Path Analysis.

\begin{tabular}{llcclll}
\hline & & Beta & T-val & L.L & U. L & Decision \\
\hline H1 & TC -> HM & 0.133 & 2.949 & 0.048 & 0.219 & Supported \\
H3 & TEC -> HM & 0.232 & 4.437 & 0.131 & 0.335 & Supported \\
H2 & TTF -> HM & 0.214 & 4.089 & 0.114 & 0.312 & Supported \\
H4 & HM -> CI & -0.048 & 1.347 & -0.12 & 0.023 & Not Sup- \\
& & & & & & ported \\
H5 & CI -> AU & -0.084 & 2.565 & -0.146 & -0.014 & Supported \\
H6 & PS\&IP -> CI & 0.168 & 3.259 & 0.071 & 0.264 & Supported \\
H7 & PS\&IP -> AU & -0.392 & 8.328 & -0.476 & -0.294 & Supported \\
H8 & FC -> CI & 0.27 & 5.478 & 0.18 & 0.368 & Supported \\
H9 & FC -> AU & -0.249 & 6.443 & -0.33 & -0.181 & Supported
\end{tabular}




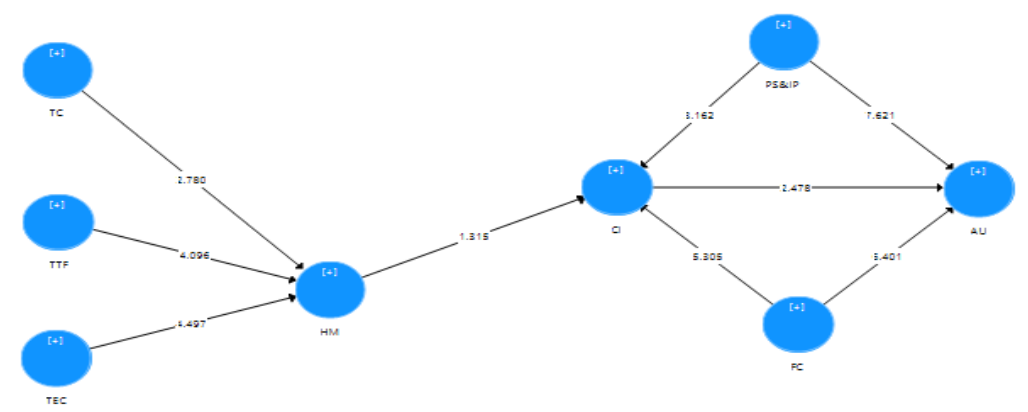

Fig. 3 Structural Model Assessment

\section{Discussion}

Since 1980, Information Technology emerged as the 'leapfrog' in the industrial revolution era that eventually transformed the entire working structure and design across the globe [96]. With time, it becomes manifest that the desideratum and significance of IT urge all the industries (irrespective of manufacturing or service) to invest millions of dollars in developing and sustaining the IT system for sustainable competitive advantage [21]. Among all other industries, the restaurant industry is considered one of the leading and fastest-growing industries, especially in the US that contributed almost four percent of the total US GDP in 2016 [97]. To escalate the progression of the restaurant industry, it becomes a dire need to adopt and integrate information and communication technologies (ICT) into their system, design and operation for significant business growth [98-100].

Technological advancements have influenced the restaurant businesses in multiple ways; improvements in computer capabilities, cost reduction, revenue generation and the impartment of better-quality services [101,102]. Furthermore, the more in-depth predilection of IT innovation in the US restaurant industry transformed the entire customer feedback systems, business management applications, marketing management systems, restaurant operation systems, revenue management system, inventory management tools, integrated cost control software, human resources management systems, $\mathrm{BOH}$ management systems [103,104]. Despite the extensive realization realization and adoption of IT by the restaurants' businesses of the US, there is still a need to continually innovate and develop the business policies, procedures, operations, products, and services with the high-tech systems. As Bilgihan and Nejad [105] reported, the restaurant industry still feels reluctant in IT adoption and its continuous usage due to increasing cost, lack of facilitating conditions, and security and privacy concerns.

In this regard, the current study intends to examine the comprehensive framework about the factors and determinants that impulse the users (employees) motivation to adopt information technology and continue its usage in different types of US restaurants. Furthermore, this study dig out the pre-technology adoption and post-technology adoption behaviors of employees. The pre-technology adoption behaviors are further classified as; task characteristics, task technology fit, and technology characteristics proposed as exogenous determinants of hedonic motivation. According to Oerlemans and Bakker [32], task characteristics are the features/attributes of a task that can only be performed/achieved using Information Communication Technologies (ICTs). Whereas Hedonic Motivation (HM) reflects fun and happiness by using ICTs that will ultimately 
enhance the job satisfaction and performance level. It is obvious that task characteristics of an individual boost the motivation level to use information technologies in routine business operations and for long-run sustainable business outcomes. In the current study, task characteristics are a significant contributor/factor that affects the hedonic motivation of an individual related to ICTs. The results of these studies are aligned with former studies $[31,32,106]$. In addition, Task Technology-Fit (TFT) is an individual perception about a new/emerging technology that acts as an immense contributor/encouragement for an individual to continue using ICTs in their routine job/business operations [37,107-109]. The same result is highlighted in the current study about the strong association of TFT and hedonic motivation. Furthermore, technology characteristics refer to the features of the technological tools (either hardware or software) that facilitate individuals to carry out their particular task within specified limitations. The current study extended the logical frameworks presented by former scholars $[43,110,111]$ about the relationship of technology characteristics and individuals' preference and intention (hedonic motivation) to use technology at the job and in the future. Overall, it is examined that pre-technology adoption behaviors are the strong predictors/boosters of employee's motivation to keep technology usage.

The phenomenon of continuance intention of technology usage (currently and in future) and its actual usage is widely studied in different industries i.e., banking, education, tourism etc., that is characterized by the individual perception, sense of excitement and inclination towards new technology. The current study presented the direct and indirect association of hedonic motivation, continuance intention and actual usage of ITCs in the context of the restaurant industry of USA. The results negate the direct association between hedonic motivation and continuance intention, which is inconsistent with earlier research investigations [112-115]. Insignificant relation between hedonic motivation and continuance intention is might be associated with the technology tools used at workplace for the task performance which are not enough user-friendly or not suitable for the common use in routine life. It can also occur because of its organizational-specific design or problem-centered format. While, the direct association of continuance intention and actual usage of ICTs is found in the results of the current study that was supported and evidenced by the previous researchers [61,116-119].

Moreover, in the context of post-adoption behaviors it is also investigated that how perceived security and privacy factors and facilitating condition of technology make their users more inclined to continue with the usage of information technology. The study's findings demonstrated the significant effect on the magnitude of continuance intention and actual usage of technology for effective job performance. The findings as mentioned above, the above-mentioned findings supported the research output of former results [120-122] for the direct impact of perceived security and information privacy on continuance intention and actual usage of ICT. Likewise, the findings of the current study for the positive impact of facilitating condition (referred to the availability of required resources and infrastructure for an individual to adapt and exploit the new/emerging technologies) on continuance intention and actual usage of ICTs reinforced the research output of earlier studies $[123,124]$. Based on the theoretical explanation and statistical findings, it may conclude that our all hypotheses (HI to H9) are supported and accepted except $\mathrm{H} 4$ for the direct association of hedonic motivation and continuance intention of technology adoption in the context of the restaurant industry in USA.

\subsection{Academic Contribution}

The study's findings draw numerous academic contributions on the comprehensive model of pre-technology adoption and post-technology adoption behaviors of users (employees) in the context of the restaurant industry of the USA. This study highlighted that existing literature is insufficient to present the integrated mechanism and boosters that motivate and encourage the employee's confidence for the technology adoption and to continue with the usage of ICTs at their workplace. From the theoretical perspective, 
this study enriched the literature about the factors that affect hedonic motivation of employees for technology adoption, its continuance intention and actual usage. Furthermore, this study added that perceived security and information privacy have a significant impact on technology adoption and the positive impact of facilitating condition on continuance intention of technology adoption and its actual usage. Moreover, this study extensively focuses on the 'restaurant industry' to present the conceptual mechanism to revolutionize and innovate the service structure by adopting and exploiting emerging ICTs for sustainable competitive advantage.

\subsection{Practical Contribution}

This study put forward several practical implications for the policymakers, practitioners and professionals for the right deployment, adoption and exploitation of emerging technologies for the sustainable competitive advantage. This study anticipated the sound contribution for the entrepreneurs/restaurant interested in continuous innovation of business practices, service structure, or payment mechanism to revolutionize the entire restaurant industry by identifying the factors to boost post adoption behavior. This study presents the plentiful recommendations for the managers to hire IT proficient staff, train them for the emerging technologies as the artificial industry is going to revolutionize the entire business world.

Policy makers should frame policies for the efficient and effective utilization of ICTs at workplace and offer magnificent compensation/reward structure as a motivational tool for the best IT user/performer for the organizational competitiveness [125,126]. A thorough understanding of the integrated technology continuance model (TCM) implies the need to instigate the coherent and robust culture of 'physical laboring minuses for the emperor IT enriched business world. Restaurants are proposed to develop the comprehensive training videos for the staff and the potential customers characterized by the section of 'frequently asked question' to enhance the user familiarity with the robust system of ICTs. They are also required to monitor and ensure the proper privacy and security checks on the official/customer's data to maintain confidentiality and anonymity. Furthermore, managers should identify the user's pre-adoption expectations and deliver them accordingly, ultimately leading to higher satisfaction level and continuous technology usage.

\subsection{Limitations and Future Research Directions}

Although this study successfully achieved its objectives, its potential limitation must be heed to posit the research direction for upcoming researchers/scholars. Firstly, this study employed a quantitative research approach to find out the causal mechanism of various constructs (factors of pre-technology adoption behaviors, hedonic motivation, post-technology adoption behaviors, facilitating conditions, perceived security and privacy) that can be extended to the exploration of other emerging potential constructs of technological-interest, set of individual differences, behavioral aspects etc. Secondly, this study used a theoretical lens of technology continuance theory (TCT) and task technology-fit (TFT) to present the integrated technology continuance model (TCM) in the context of the restaurant industry of the USA that can be broadened contextually and geographically to explore the pre-technology adoption and post-technology adoption behaviors of users from other industries/geographical boundaries. Additionally, this study proposed several practices; training videos, frequently asked questions, ICTs plus culture, strong security/privacy checks, engagement of IT proficient staff, proper training and development program, adequate compensation/benefits for best performers to enhance the continuance intention of technology usage. Upcoming researchers are required to test the impact of these practices on the usage of information technology with continuance intention.

\subsection{Conclusion}


IT advancements play a pivotal role in the sing the restaurant industry by the proliferation of institutional structure, system, design and services. The dire need of the era is to transform the visionary landscape of restaurants from revenue generation to sustainable business outcomes. To fit in with the new wave of IT momentum, this study extended the TCT and TTF model to present an integrated technology continuance model (TCM) about the pre-technology adoption and post-technology adoption behaviors of users (employees) in the context of the restaurant industry located within US (United States). Furthermore, the findings of the study revealed that perceived security, information privacy and facilitating conditions must be taken into account to boost the usage of information technology with continuance intention.

Funding: The open access of this research is supported by the SPEV project 2021 at the Faculty of Informatics and Management, University of Hradec Kralove, Czech Republic.

Institutional Review Board Statement: Not applicable.

Informed Consent Statement: Not applicable.

Data Availability Statement: Data is available from the authors and can be provided on request.

Conflicts of Interest: The authors declare no conflict of interest.

\section{References}

1. Garrett-Peltier, H. Green versus brown: Comparing the employment impacts of energy efficiency, renewable energy, and fossil fuels using an input-output model. Econ. Model. 2017, 61, 439-447.

2. Sheel, A. Journal of Hospitality Financial Management The Professional Refereed Journal of the International Association of Hospitality Financial Management Educators Volume 26 I Issue 1 Article 1 Summer 2018 Recommended Citation Sheel. J. Hosp. Financ. Manag. 2018, 26.

3. Cavusoglu, M. An analysis of technology applications in the restaurant industry. J. Hosp. Tour. Technol. 2019, 10, $45-72$.

4. Aratuo, D.N.; Etienne, X.L. Industry level analysis of tourism-economic growth in the United States. Tour. Manag. 2019, 70, 333-340.

5. Kleemans, M.; Thornton, R.L. Who Belongs? The Determinants of Selective Membership into the National Bureau of Economic Research. AEA Pap. Proc. 2021, 111, 117-122.

6. Law, R.; Leung, D.; Chan, I.C.C. Progression and development of information and communication technology research in hospitality and tourism: A state-of-the-art review. Int. J. Contemp. Hosp. Manag. 2020, 32, 511-534.

7. Ivanov, S. Ultimate transformation: How will automation technologies disrupt the travel, tourism and hospitality industries? Zeitschrift für Tour. 2019, 11, 25-43.

8. Tan, T.F.; Netessine, S. At Your Service on the Table: Impact of Tabletop Technology on Restaurant Performance. Manage. Sci. 2020, 66, 4496-4515.

9. Yang, F.X. Effects of Restaurant Satisfaction and Knowledge Sharing Motivation on eWOM Intentions: The Moderating Role of Technology Acceptance Factors. J. Hosp. Tour. Res. 2017, 41, 93-127.

10. Patil, S.; Wongsurawat, W. Information technology (IT) outsourcing by business process outsourcing/information technology enabled services (BPO/ITES) firms in India: A strategic gamble. J. Enterp. Inf. Manag. 2015, 28, 60-76. 
11. Madhavaram, S.; Appan, R. Deconstructing Research on Information Technology (IT) Capabilities: Implications for Marketing Strategy. In Proceedings of the 2010 Academy of Marketing Science (AMS) Annual Conference; Springer International Publishing, 2015; pp. 25-25.

12. Tuomi, A.; Tussyadiah, I.; Stienmetz, J. Service Robots and the Changing Roles of Employees in Restaurants: A Cross Cultural Study; 2020; Vol. 17;.

13. Ashcroft, E.; Tuomi, A.; Wang, M.; Solnet, D. Resistance to the Adoption of ICTs in Independent Restaurants: Insights from China \& the UK; 2019; Vol. 16;.

14. Makki, A.M.; Ozturk, A.B.; Singh, D. Role of risk, self-efficacy, and innovativeness on behavioral intentions for mobile payment systems in the restaurant industry. J. Foodserv. Bus. Res. 2016, 19, 454-473.

15. Lambert, T.E. Does Innovation Chase Profits, or Do Profits Chase Innovation?; 2018; Vol. 7;

16. Chaouali, W. Once a user, always a user: Enablers and inhibitors of continuance intention of mobile social networking sites. Telemat. Informatics 2016, 33, 1022-1033.

17. Al-rahmi, W.M.; Zeki, A.M.; Alias, N.; Saged, A.A. Information Technology Usage in the Islamic Perspective: A Systematic Literature Review. Anthropol. 2017, 29, 27-41.

18. Bello-Pintado, A.; Kaufmann, R.; Merino Diaz de Cerio, J. Firms' entrepreneurial orientation and the adoption of quality management practices: Empirical evidence from a Latin American context. Int. J. Qual. Reliab. Manag. 2018, 35, 1734-1754.

19. Johnson, V.L.; Woolridge, R.W.; Wang, W.; Bell, J.R. The Impact of Perceived Privacy, Accuracy and Security on the Adoption of Mobile Self-Checkout Systems. J. Innov. Econ. Manag. 2020, n³1, 221.

20. Ukpabi, D.; Olaleye, S.; Karjaluoto, H. Factors Influencing Tourists' Intention to Use COVID-19 Contact Tracing App. In Information and Communication Technologies in Tourism 2021; Springer International Publishing, 2021; pp. 504-516.

21. Moreno, P.; Tejada, P. Reviewing the progress of information and communication technology in the restaurant industry. J. Hosp. Tour. Technol. 2019, 10, 673-688.

22. Goodhue, D.L. Understanding User Evaluations of Information Systems; 1995; Vol. 41;.

23. Liao, C.; Palvia, P.; Chen, J.L. Information technology adoption behavior life cycle: Toward a Technology Continuance Theory (TCT). Int. J. Inf. Manage. 2009, 29, 309-320.

24. Daragmeh, A.; Sági, J.; Zéman, Z. Continuous Intention to Use E-Wallet in the Context of the COVID-19 Pandemic: Integrating the Health Belief Model (HBM) and Technology Continuous Theory (TCT). J. Open Innov. Technol. Mark. Complex. 2021, 7, 132.

25. Lin, W.S. Perceived fit and satisfaction on web learning performance: IS continuance intention and task-technology fit perspectives. Int. J. Hum. Comput. Stud. 2012, 70, 498-507.

26. Rahi, S.; Khan, M.M.; Alghizzawi, M. Extension of technology continuance theory (TCT) with task technology fit (TTF) in the context of Internet banking user continuance intention. Int. J. Qual. Reliab. Manag. 2020, 38, 986-1004.

27. Lu, H.P.; Yang, Y.W. Toward an understanding of the behavioral intention to use a social networking site: An extension of task-technology fit to social-technology fit. Comput. Human Behav. 2014, 34, 323-332.

28. Brown, S.A.; Venkatesh, V.; Hoehle, H. Technology adoption decisions in the household: A seven-model comparison. J. Assoc. Inf. Sci. Technol. 2015, 66, 1933-1949. 
29. Venkatesh, V.; Thong, J.Y.L.; Xu, X. Consumer Acceptance and Use of Information Technology. MIS Q. 2012, 36, 157-178.

30. Hackman, J.R.; Oldham, G.R. Development of the Job Diagnostic Survey. J. Appl. Psychol. 1975, 60, 159-170.

31. Nasir, N.; Halimatussakdiah, H.; Suryani, I.; Zuhra, S.E.; Armia, S.; Mahdani, M. How Intrinsic Motivation and Innovative Work Behavior Affect Job Performance.; Atlantis Press, 2019; pp. 606-612.

32. Oerlemans, W.G.M.; Bakker, A.B. Motivating job characteristics and happiness at work: A multilevel perspective. J. Appl. Psychol. 2018, 103, 1230-1241.

33. Sarti, D.; Torre, T. ICT Use and Job Satisfaction. The Moderating Role of Task Characteristics. In Lecture Notes in Information Systems and Organisation; Springer Heidelberg, 2019; Vol. 27, pp. 11-26.

34. Tam, C.; Oliveira, T. Does culture influence m-banking use and individual performance? Inf. Manag. 2019, 56, 356-363.

35. Tripathi, S.; Jigeesh, N. Task-Technology Fit (TTF) Model To Evaluate Adoption of Cloud Computing: A Multi-Case Study; 2015; Vol. 10;

36. Lee, D.Y.; Lehto, M.R. User acceptance of YouTube for procedural learning: An extension of the Technology Acceptance Model. Comput. Educ. 2013, 61, 193-208.

37. Ratna, S.; Astuti, E.S.; Utami, H.N.; Rahardjo, K.; Arifin, Z. Characteristics of tasks and technology as a driver of task-technology fit and the use of the hotel reservation information system. VINE J. Inf. Knowl. Manag. Syst. 2018, 48, 579-595.

38. Martins, C.; Oliveira, T.; Popovič, A. Understanding the internet banking adoption: A unified theory of acceptance and use of technology and perceived risk application. Int. J. Inf. Manage. 2014, 34, 1-13.

39. Cheng, Y.M. Understanding cloud ERP continuance intention and individual performance: a TTF-driven perspective. Benchmarking 2020, 27, 1591-1614.

40. Sharif, A.; Afshan, S.; Qureshi, M.A. Acceptance of learning management system in university students: An integrating framework of modified UTAUT2 and TTF theories. Int. J. Technol. Enhanc. Learn. 2019, 11, $201-229$.

41. Alazab, M.; Alhyari, S.; Awajan, A.; Abdallah, A.B. Blockchain technology in supply chain management: an empirical study of the factors affecting user adoption/acceptance. Cluster Comput. 2021, 24, 83-101.

42. Goodhue, D.L. Development and measurement validity of a task-technology fit instrument for user evaluations of information systems. Decis. Sci. 1998, 29, 105-138.

43. Yen, D.C.; Wu, C.S.; Cheng, F.F.; Huang, Y.W. Determinants of users' intention to adopt wireless technology: An empirical study by integrating TTF with TAM. Comput. Human Behav. 2010, 26, 906-915.

44. Ramayah, T. Interface Characteristics, Perceived Ease of Use and Intention to Use an Online Library in Malaysia. Inf. Dev. 2006, 22, 123-133.

45. Tam, C.; Oliveira, T. Understanding the impact of $\mathrm{m}$-banking on individual performance: DeLone \& McLean and TTF perspective. Comput. Human Behav. 2016, 61, 233-244.

46. Lin, X.; Wu, R.Z.; Lim, Y.T.; Han, J.; Chen, S.C. Understanding the sustainable usage intention of mobile payment technology in Korea: Cross-countries comparison of Chinese and Korean users. Sustain. 2019, 11, 5532.

47. Wixom, B.H.; Todd, P.A. A theoretical integration of user satisfaction and technology acceptance. Inf. Syst. Res. 2005, 16, 85-102.

48. Rahi, S.; Othman Mansour, M.M.; Alharafsheh, M.; Alghizzawi, M. The post-adoption behavior of internet 
banking users through the eyes of self-determination theory and expectation confirmation model. J. Enterp. Inf. Manag. 2021.

49. Hassan, H.A.; Zhang, X.; Ahmad, A.B.; Liu, B. Public Service Motivation and Employee Change-Supportive Intention: Utilizing the Theory of Planned Behavior. Public Pers. Manage. 2021, 50, 283-304.

50. Wang, Q.; Khan, M.S. Impact of motivation and technology factors to predict satisfaction and continued intentions toward online courses. Int. J. Res. Bus. Soc. Sci. (2147-4478) 2021, 10, 501-513.

51. Al-Nuaimi, M.N.; Al-Emran, M. Learning management systems and technology acceptance models: A systematic review. Educ. Inf. Technol. 2021, 1-35.

52. Sharif, A.; Raza, S.A. The influence of hedonic motivation, self-efficacy, trust and habit on adoption of internet banking: A case of developing country. Int. J. Electron. Cust. Relatsh. Manag. 2017, 11, 1-22.

53. Rahi, S.; Khan, M.M.; Alghizzawi, M. Extension of technology continuance theory (TCT) with task technology fit (TTF) in the context of Internet banking user continuance intention. Int. J. Qual. Reliab. Manag. 2021, 38, 986-1004.

54. Brown, S.A.; Venkatesh, V. Model of adoption of technology in households: A baseline model test and extension incorporating household life cycle. MIS Q. Manag. Inf. Syst. 2005, 29, 399-426.

55. Skoumpopoulou, D.; Skoumpopoulou, D.; Wong, A.; Ng, P.; Lo, M. Factors that affect the acceptance of new technologies in the workplace: a... Int. J. Educ. Dev. using ICT 2018, 14.

56. Aldholay, A.; Isaac, O.; Abdullah, Z.; Abdulsalam, R.; Al-Shibami, A.H. An extension of Delone and McLean IS success model with self-efficacy: Online learning usage in Yemen. Int. J. Inf. Learn. Technol. 2018, 35, $285-304$.

57. Irani, Z.; Dwivedi, Y.K.; Williams, M.D. Understanding consumer adoption of broadband: An extension of the technology acceptance model. J. Oper. Res. Soc. 2009, 60, 1322-1334.

58. Mailizar, M.; Almanthari, A.; Maulina, S. Examining teachers' behavioral intention to use e-learning in teaching of mathematics: An extended tam model. Contemp. Educ. Technol. 2021, 13, 1-16.

59. Al-Maroof, R.S.; Salloum, S.A. An Integrated Model of Continuous Intention to Use of Google Classroom. In Studies in Systems, Decision and Control; Springer, 2021; Vol. 295, pp. 311-335.

60. Liu, H.; Shao, M.; Liu, X.; Zhao, L. Exploring the Influential Factors on Readers' Continuance Intentions of E-Book APPs: Personalisation, Usefulness, Playfulness, and Satisfaction. Front. Psychol. 2021, 12, 640110.

61. Farah, M.F.; Hasni, M.J.S.; Abbas, A.K. Mobile-banking adoption: empirical evidence from the banking sector in Pakistan. Int. J. Bank Mark. 2018, 36, 1386-1413.

62. Febrianto, G.; Hidayatullah, S.; Ardianto, Y.T. The Effect of Intention to Usage to Actual Usage E-Purchasing Application. Artic. Int. J. Sci. Eng. Res. 2018, 9.

63. Dehghani, M. Exploring the motivational factors on continuous usage intention of smartwatches among actual users. Behav. Inf. Technol. 2018, 37, 145-158.

64. Shin, D.; Hwang, Y. The effects of security and traceability of blockchain on digital affordance. Online Inf. Rev. 2020, 44, 913-932.

65. Degirmenci, K. Mobile users' information privacy concerns and the role of app permission requests. Int. J. Inf. Manage. 2020, 50, 261-272.

66. Bhowal, C. Information and Communication Technology (ICT): Opportunities or Threats for Women Entrepreneurs - An Emperical Survey. SSRN Electron. J. 2020. 
67. Arpaci, I.; Kilicer, K.; Bardakci, S. Effects of security and privacy concerns on educational use of cloud services. Comput. Human Behav. 2015, 45, 93-98.

68. Almadhoun, N.M.; Dominic, P.D.D.; Lai, F.W. Investigation of perceived security, privacy and trust on social networking sites for stakeholder relationships development in malaysian universities. Int. J. Bus. Inf. Syst. 2014, $15,1-21$.

69. Dhillon, G.; Oliveira, T.; Susarapu, S.; Caldeira, M. Deciding between information security and usability: Developing value based objectives. Comput. Human Behav. 2016, 61, 656-666.

70. Princi, E.; Krämer, N.C. Out of Control - Privacy Calculus and the Effect of Perceived Control and Moral Considerations on the Usage of IoT Healthcare Devices. Front. Psychol. 2020, 11.

71. Peñarroja, V.; Sánchez, J.; Gamero, N.; Orengo, V.; Zornoza, A.M. The influence of organizational facilitating conditions and technology acceptance factors on the effectiveness of virtual communities of practice. Behav. Inf. Technol. 2019, 38, 845-857.

72. onaolapo, sodiq; Oyewole, O. Performance Expectancy, Effort Expectancy, and Facilitating Conditions as Factors Influencing Smart Phones Use for Mobile Learning by Postgraduate Students of the University of Ibadan, Nigeria. Interdiscip. J. e-Skills Lifelong Learn. 2018, 14, 095-115.

73. Vairetti, C.; González-Ramírez, R.G.; Maldonado, S.; Álvarez, C.; Vo $\beta$, S. Facilitating conditions for successful adoption of inter-organizational information systems in seaports. Transp. Res. Part A Policy Pract. 2019, 130, 333-350.

74. Sukendro, S.; Habibi, A.; Khaeruddin, K.; Indrayana, B.; Syahruddin, S.; Makadada, F.A.; Hakim, H. Using an extended Technology Acceptance Model to understand students' use of e-learning during Covid-19: Indonesian sport science education context. Heliyon 2020, 6, e05410.

75. Aboelmaged, M.; Gebba, T.R. Mobile Banking Adoption: An Examination of Technology Acceptance Model and Theory of Planned Behavior. Int. J. Bus. Res. Dev. 2013, 2.

76. Et.al, A.M. The Behavioral Intention's Role:Facilitating Condition and Use of E-Government Services among SMEs in Saudi Arabia. Turkish J. Comput. Math. Educ. 2021, 12, 1520-1528.

77. Merhi, M.; Hone, K.; Tarhini, A.; Ameen, N. An empirical examination of the moderating role of age and gender in consumer mobile banking use: a cross-national, quantitative study. J. Enterp. Inf. Manag. 2020, ahead-of-p.

78. Bere, A. Applying an Extended Task-Technology Fit for Establishing Determinants of Mobile Learning: An Instant Messaging Initiative. J. Inf. Syst. Educ. 2018, 29.

79. Goodhue, D.L.; Thompson, R.L. Task-technology fit and individual performance. MIS Q. Manag. Inf. Syst. 1995, $19,213-233$.

80. Venkatesh, V.; Thong, J.Y.L.; Xu, X. Consumer acceptance and use of information technology: Extending the unified theory of acceptance and use of technology. MIS Q. Manag. Inf. Syst. 2012, 36, 157-178.

81. Kim, M.J.; Hall, C.M. A hedonic motivation model in virtual reality tourism: Comparing visitors and non-visitors. Int. J. Inf. Manage. 2019, 46, 236-249.

82. Cobanoglu, C.; Yang, W.; Shatskikh, A.; Agarwal, A.; Cobanoglu, C.; Yang, W.;; Shatskikh, A.; Are Consumers Ready for Mobile Payment? An Examination of Consumer Acceptance of Mobile Payment Technology in Restaurant Industry; 2015; Vol. 31;

83. Johnson, G.A.; Shriver, S.K.; Du, S. Consumer privacy choice in online advertising: Who opts out and at what 
cost to industry? Mark. Sci. 2020, 39, 33-51.

84. Johnson, V.L.; Kiser, A.; Washington, R.; Torres, R. Limitations to the rapid adoption of M-payment services: Understanding the impact of privacy risk on M-Payment services. Comput. Human Behav. 2018, 79, $111-122$.

85. Almarri, K.; Aljarman, M.; Boussabaine, H. Emerging contractual and legal risks from the application of building information modelling. Eng. Constr. Archit. Manag. 2019, 26, 2307-2325.

86. Palau-Saumell, R.; Forgas-Coll, S.; Sánchez-García, J.; Robres, E. User Acceptance of Mobile Apps for Restaurants: An Expanded and Extended UTAUT-2. Sustainability 2019, 11, 1210.

87. Ashraf, M.; Ahmad, J.; Sharif, W.; Raza, A.A.; Salman Shabbir, M.; Abbas, M.; Thurasamy, R. The role of continuous trust in usage of online product recommendations. Online Inf. Rev. 2020, 44, 745-766.

88. Tarhini, A.; El-Masri, M.; Ali, M.; Serrano, A. Extending the utaut model to understand the customers' acceptance and use of internet banking in lebanon a structural equation modeling approach. Inf. Technol. People 2016, 29, 830-849.

89. Ali, F.; Rasoolimanesh, S.M.; Sarstedt, M.; Ringle, C.M.; Ryu, K. An assessment of the use of partial least squares structural equation modeling (PLS-SEM) in hospitality research. Int. J. Contemp. Hosp. Manag. 2018, 30, 514-538.

90. Sarstedt, M.; Ringle, C.; Henseler, J.; Hair, J.F. “On the emancipation of PLS-SEM.” Long Range Plan. (in Press. 2014, 47, 154-160.

91. Hair, J.F.; Risher, J.J.; Sarstedt, M.; Ringle, C.M. When to use and how to report the results of PLS-SEM. Eur. Bus. Rev. 2019, 31, 2-24.

92. Hair, J.F.; Hult, G.T.M.; Ringle, C.; Sarstedt, M. A primer on partial least squares structural equation modeling (PLS-SEM); Sage Publications, 2016; ISBN 1483377466.

93. Henseler, J.; Ringle, C.M.; Sarstedt, M. A new criterion for assessing discriminant validity in variance-based structural equation modeling. J. Acad. Mark. Sci. 2015, 43, 115-135.

94. Ringle, C.M.; Sarstedt, M.; Straub, D.W. A critical look at the use of PLS-SEM in MIS quarterly. MIS Q. Manag. Inf. Syst. 2012, 36.

95. Ringle, C.; Wende, S.; Will, A. Smart-PLS Version 2.0 M3. Univ. Hambg. 2005.

96. Çavuşoğlu, Ü. A new hybrid approach for intrusion detection using machine learning methods. Appl. Intell. 2019, 49, 2735-2761.

97. Biando, G. An Analysis of Restaurant Food Safety Practices Within Full-Service Restaurants During Peak Business Hours in San Diego County, California. 2018.

98. Roztocki, N.; Weistroffer, H.R. Information and Communication Technology in Transition Economies: An Assessment of Research Trends. Inf. Technol. Dev. 2015, 21, 330-364.

99. Jones, P.; Wynn, M.; Hillier, D.; Comfort, D. The Sustainable Development Goals and Information and Communication Technologies. Indones. J. Sustain. Account. Manag. 2017, 1, 1.

100. Hambrick, D.C. Top Management Teams. In Wiley Encyclopedia of Management; John Wiley \& Sons, Ltd, 2015; pp. 1-2.

101. Jasonos, M.; Mccormick, R. Technology Integration for Restaurants \& Hospitality Industry in the Year 2025 Degree programme Degree Programme in Tourism; Haaga-Helia ammattikorkeakoulu, 2017;

102. Amirı, M.H. An exploratory study of digital technology applications used in restaurants and cafes in Ankara. 
2019.

103. Davis, D.; Chen, G.; Hauff, C.; Houben, G.J. Activating learning at scale: A review of innovations in online learning strategies. Comput. Educ. 2018, 125, 327-344.

104. Nisar, Q.A.; Nasir, N.; Jamshed, S.; Naz, S.; Ali, M.; Ali, S. Big data management and environmental performance: role of big data decision-making capabilities and decision-making quality. J. Enterp. Inf. Manag. 2020.

105. Bilgihan, A.; Nejad, M. Innovation in hospitality and tourism industries. J. Hosp. Tour. Technol. $2015,6$.

106. Stoermer, S.; Lauring, J.; Selmer, J. Job characteristics and perceived cultural novelty: exploring the consequences for expatriate academics' job satisfaction. Int. J. Hum. Resour. Manag. 2020.

107. Isaac, O.; Abdullah, Z.; Ramayah, T.; Mutahar, A.M. Internet usage, user satisfaction, task-technology fit, and performance impact among public sector employees in Yemen. Int. J. Inf. Learn. Technol. 2017, 34, $210-241$.

108. Isaac, O.; Aldholay, A.; Abdullah, Z.; Ramayah, T. Online learning usage within Yemeni higher education: The role of compatibility and task-technology fit as mediating variables in the IS success model. Comput. Educ. 2019, $136,113-129$.

109. Spies, R.; Grobbelaar, S.; Botha, A. A Scoping Review of the Application of the Task-Technology Fit Theory. In Proceedings of the Lecture Notes in Computer Science (including subseries Lecture Notes in Artificial Intelligence and Lecture Notes in Bioinformatics); Springer, 2020; Vol. 12066 LNCS, pp. 397-408.

110. Feder Mayer, V. Mobile technology, games and nature areas: The tourist perspective Tecnologia móvel, games e espaços naturais: a perspectiva do turista Marcelo de Oliveira Nunes; Vol. 10;.

111. Oliveira, T.; Thomas, M.; Baptista, G.; Campos, F. Mobile payment: Understanding the determinants of customer adoption and intention to recommend the technology. Comput. Human Behav. 2016, 61, 404-414.

112. Al-Azawei, A.; Alowayr, A. Predicting the intention to use and hedonic motivation for mobile learning: A comparative study in two Middle Eastern countries. Technol. Soc. 2020, 62, 101325.

113. Dayour, F.; Adongo, C.A.; Agyeiwaah, E. Continuous intention to use mobile money (MM) services: Driving factors among small and medium-sized tourism and hospitality enterprises (SMTHEs). Africa J. Manag. 2020, 6, 85-114.

114. Riffai, M.M.M.A.; Grant, K.; Edgar, D. Big TAM in Oman: Exploring the promise of on-line banking, its adoption by customers and the challenges of banking in Oman. Int. J. Inf. Manage. 2012, 32, 239-250.

115. Tayseer, F.; Ayasrah, M. Exploring E-Learning Readiness as Mediating between Trust, Hedonic Motivation, Students' Expectation, and Intention to Use Technology in Taibah University. J. Educ. Soc. Policy $2020,7$.

116. Prodanova, J.; Ciunova-Shuleska, A.; Palamidovska-Sterjadovska, N. Enriching m-banking perceived value to achieve reuse intention. Mark. Intell. Plan. 2019, 37, 617-630.

117. Halawi, L.; McCarthy, R.; Farah, J. Information Systems Continuance: Faculty Perceptions of Canvas. Issues Inf. Syst. 2018, 19.

118. Mok, A.; De Cremer, D. The bonding effect of money in the workplace: priming money weakens the negative relationship between ostracism and prosocial behaviour. Eur. J. Work Organ. Psychol. 2016, 25, $272-286$.

119. Naa, A.; Ayi-Bonte, A.; Jinjin, W.; Lugu, B.K.; Tahirou, S.C.; Bondzie-Micah, V. Utilization of Social Media Platforms for Local Government Engagements: An Empirical Study of the Accra Metropolitan Assembly. North Am. Acad. Res. 2020, 3, 303-324.

120. Susanto, A.; Chang, Y.; Ha, Y. Determinants of continuance intention to use the smartphone banking services: 
An extension to the expectation-confirmation model. Ind. Manag. Data Syst. 2016, 116, 508-525.

121. Yang, H.L.; Lin, S.L. User continuance intention to use cloud storage service. Comput. Human Behav. 2015, 52, 219-232.

122. Kumar, A.; Adlakaha, A.; Mukherjee, K. The effect of perceived security and grievance redressal on continuance intention to use M-wallets in a developing country. Int. J. Bank Mark. 2018, 36, 1170-1189.

123. Ambarwati, R.; Dian HARJA, Y.; Thamrin, S. The Role of Facilitating Conditions and User Habits: A Case of Indonesian Online Learning Platform The Role of Facilitating Conditions and User Habits: A Case of Indonesian Online Learning Platform*. J. Asian Financ. 2020, 7, 481-489.

124. Bozkurt, A.; Jung, I.; Xiao, J.; Vladimirschi, V.; Schuwer, R.; Egorov, G.; Lambert, S.R.; Al-Freih, M.; Pete, J.; Olcott, D.; et al. A global outlook to the interruption of education due to COVID-19 Pandemic: Navigating in a time of uncertainty and crisis. Asian J. Distance Educ. 2020, 15, 2020.

125. Naz, S.; Li, C.; Nisar, Q.A.; Khan, M.A.S.; Ahmad, N.; Anwar, F. A Study in the Relationship Between Supportive Work Environment and Employee Retention: Role of Organizational Commitment and Person-Organization Fit as Mediators. SAGE Open 2020, 10.

126. Li, C.; Naz, S.; Khan, M.A.S.; Kusi, B.; Murad, M. An empirical investigation on the relationship between a high-performance work system and employee performance: measuring a mediation model through partial least squares-structural equation modeling. Psychol. Res. Behav. Manag. 2019, 12, 397-416. 